\title{
PSYCHE
}

\begin{tabular}{lll}
\hline Vol. 92 & 1985 & No. 4 \\
\hline
\end{tabular}

\section{CRYPTIC PHRAGMOSIS: THE STRUCTURAL MODIFICATIONS}

\author{
By Diana E. Wheeler* and Bert Hölldobler \\ Museum of Comparative Zoology, \\ Harvard University, \\ Cambridge, Massachusetts 02138
}

\section{INTRODUCTION}

Cephalotini is an exclusively arboreal tribe of Neotropical ants that has specialized in passive defense. In the largest genus, Zacryptocerus, the entire body is heavily armoured and the expanded head surface of the soldier is particularly suited for blocking the nest entrance. Soldiers act as living doors, closing off nest entrances with their heads. Wheeler (1927) termed this phenomenon phragmosis. The most extremely modified heads within Zacryptocerus are found in the subgenus Cyathomyrmex, which is characterized by a completely rimmed, saucer-shaped, cephalic disc on the heads of soldiers and queens (Kempf, 1958).

Wheeler (1942) was the first to notice that in two species in this group queens and older soldiers tend to accumulate dirt on their heads. He also commented that the accumulation of this material made the heads resemble the bark of a plant and implied that the debris camouflaged this living gate to the nest.

Recent discoveries of soil-binding pilosity in basicerotine and stegomyrmicine ants (Hölldobler and Wilson, 1986) stimulated us to look for similar dirt collecting structures on these bizarre cephalotines. This led us to the discovery of remarkable features on the

*Current address: Department of Biology, University of Southeastern Louisiana, Lafayette, Louisiana 70504.

Manuscript received by the editor August 15, 1985 
heads of soldiers and queens, unlike those described for any other ants.

\section{METHODS}

Zacryptocerus pallens porrasi was collected on Barro Colorado Island (BCI) in Panama, and Z. varians was collected on Upper Matecumbe Key, Florida. Specimens of $Z$. pallens from British Guiana, from the Florida keys, and $Z$. setulifer from Ancon, Panama, were obtained from the MCZ collections. The micrographs were taken with an AMR 1000 A scanning electron microscope.

\section{RESULTS}

Z. varians (Figs. 1-3). The heads of soldiers were covered with large, blade-like setae arched over large shallow pits. The sparse distribution of the pits gives the head a pock-marked appearance. The most remarkable feature of clean specimens was the high density of pores 1-3 $\mu$ in diameter. These are almost certainly glandular openings (Fig. 1). The density of pores was about 1 pore $/ 350 \mu^{2}$, and the total number of pores on the disc was estimated to be over 8000 . One specimen, which appeared only slightly grimy to the eye, was in fact covered with a dense tangle of material (Figs. 2, 3a) which resembled a mass of fungal filaments (mycelia). Patches of material on the head of a second specimen consisted of an encrusting layer as well as some filaments (Fig. 3b). Examination of the mat material under a light microscope revealed, however, none of the branching or internal structure indicative of a fungal origin. We suggest that the filaments are material extruded through what are apparently glandular openings.

Z. pallens (Figs. 4-6). To the eye, the head of the soldier shown in Fig. 4a appeared to be covered with a thin layer of dirt. Closer examination revealed that the surface was covered with irregular ribbons of material (Figs. 4b, 5a). Pores were visible along part of the central ridge (see Fig. 5b). Material seemed to be extruded in lumpy strands from a number of the pores (Figs. 5b, 6), supporting the suggestion that it is secretory in origin.

Z. pallens porrasi (Figs. 7-9). The two soldiers shown in Figs. 7-9 were collected from the same colony. They represent the recognizable form of $Z$. pallens that Wheeler (1942) described as the variety 
porrasi (referred to in the remainder of this paper as Z. pallens porrasi). The soldier is characterized by large brush setae on the cephalic disc (Fig. 7). Similar views of the two soldiers, one clean and one dirty, are shown in Fig. 8. In the soldier that appeared clean, the brush setae were free of accumulated material, but the surface seemed to be obscured by a thick encrusting material (Figs. $7,8 \mathrm{a})$. The second soldier had such a thick accumulation that the large brush setae were almost completely buried (Figs. 8b, 9a). The material on the head of the dirty soldier appeared fibrous (Fig. 9b), much like the material seen on the head of $Z$. varians (Fig. 3a).

$Z$. setulifer (Figs. 10-11). The MCZ collection includes 3 queens and 1 soldier of this little-known species. The heads of all 4 specimens are caked with debris. We examined one queen and found that the material encrusting the head appeared more solid than that seen in the other species. Brush setae on the head, as far as they can be seen (Fig. 10b), were not as complex as those on Z. pallens porrasi. On the thorax, where the hairs were visible, were two layers of setae: erect brush hairs and a lower layer of flattened appressed setae (Fig. 11). The same pattern was found on the thorax of the soldier.

\section{Discussion}

Wheeler (1942) was the first to suggest that the encrusting material found on the heads of soldiers and queen in two different cephalotines functioned as camouflage for the nest entrance. His description of Z. pallens var. porrasi was based primarily on the large, sparse hairs on the heads of soldiers and queens. He commented that the cephalic disk of older soldiers and the queen were often coated with "dirt and extraneous particles so that it closely resembled the bark of the plant." In addition, he gave the first description of the soldier caste for Z. setulifer and noted that the cephalic discs were encrusted with "foreign matter from exposure to the elements during guard duty at the oval nest entrance."

The soldiers, and perhaps the queen during early stages of colony development, act as living gates at colony entrances. Clean, shiny head surfaces might be more easily spotted by visual predators, such as birds and lizards, which could break open twigs for the rich reward of ant brood. The resemblance of heads to bark would effectively conceal the location of the nest and nest entrance.

The use of accumulated debris as camouflage has been found in basicerotine and stegomyrmicine ants. These are unusually slow, 
dirty ants that freeze when disturbed. The entire dorsal surface is covered with soil-binding pilosity that enhances accumulation of dirt particles (Hölldobler and Wilson, 1986). In Z. varians and $Z$. setulifer, the complex setae and the accumulation of dirt is also restricted to the exposed surface, in this case the cephalic disk. Here too, camouflage is enhanced by lack of motion, since guards remain stationary at the entrance.

\section{Pilosity}

The structure of setae on the cephalic disc differed among the four forms of Zacryptocerus we examined (varians, pallens, pallens porrasi, and setulifer). $Z$. varians and the typical form of $Z$. pallens bore setae typical of the genus: a flattened blade arched over a shallow pit. Setae of this form probably do not encourage accumulation of extraneous material on the disc surface.

Both Z. pallens porrasi and Z. setulifer, however, had upright brush setae that probably do enhance collection of material. The setae on $Z$. pallens porrasi were thick and split to the base, much like a shaving-brush. They appeared identical to hairs found in the genus Eurhopalothrix. More slender brush hairs split only near the tip are common throughout the Basicerotini (Hölldobler and Wilson, 1986). Both forms of brush hairs are correlated with soilbinding in these cryptic terrestrial ants.

In Z. varians, $Z$. pallens and Z. pallens porrasi, all hairs on the cephalic disc were of a single type. In $Z$. setulifer, there may be more than one hair type on the head, if the hair pattern is similar to that found on the thorax. One type was the erect brush hair and the other was an appressed blade-like holding seta. This double-layered arrangement is common in ants that bind soil particles to their cuticle (Hölldobler and Wilson, 1986).

Kempf (1958), in his revision of the Cephalotini, struggled with variability of pilosity and disc sculpture within the pallens complex. In the end, he lumped all forms into one species. In view of our findings, some of the confusing variation in sculpture and pilosity may be only apparent and due to varying degrees of coverage, rather than actual structural differences. The value of pilosity as a taxonomic tool may deserve re-evaluation and could be used to distinguish closely related species in what appears to be a pallens complex. 


\section{Encrusting material}

The accumulation of material on heads of soldiers and queens was common to all the species we examined. In some cases the accumulation was extreme (Fig. 8b, 10a) and in some it was slight (Figs. 1a, 3b). Remarkably, the material seemed to be internal in origin, rather than an accretion of environmental debris. The glandular origin of the material was suggested by the following aspects of external morphology, but confirmation awaits histological study. First, thousands of pores resembling glandular openings covered the head of the $Z$. varians soldier, as shown in Figs. 1b, 3b. Second, material caught in the process of extrusion was found in $Z$. pallens (Fig. 6). The diameter of the fibers in both Z. varians and Z. pallens was appropriate for the size of the pores. Finally, examination with a light microscope of the material on $Z$. varians did not suggest a fungal origin. The possibility that some of the material found in the dense mats of fibers were fungal mycelia (Fig. 8a) has not been completely eliminated, however.

The fibrous material may not be the only type of material extruded onto the disc surface. A sheet of material covering the floor of the disk was seen on some specimens of $Z$. varians (Fig. 3b). In addition, what appeared to be a blanket of thicker material coated the floor of the apparently clean specimen of $Z$. pallens porrasi (Fig. 7b). The even coating may not be confined to the queen and soldier castes. Minor workers of $Z$. varians appeared to be coated with a homogenous layer of coagulated film over the surface of the head.

The function of the fibrous material on the cephalic discs of soldiers and queens is not entirely clear. When the whole bowl of the cephalic disc is filled with material, as in $Z$. pallens porrasi and $Z$. setulifer, a camouflage role seems likely. In less extreme cases, the possibility of crypsis is less obvious. However, a thin, grimy layer may be sufficient visual or tactile camouflage in some environments.

The internal origin of the material on the cephalic discs contrasts with the extraneous origin found in the Basicerotini and Stegomyrmicini (Hölldobler and Wilson, 1986). It may be that in the arboreal environment in which all cephalotines live, suitable dirt particles are relatively scarce, and a more reliable source of camouflage material is from within. In Z. pallens porrasi, Z. setulifer, and the Basicerotini, complex setae enhance the accumulation of material, regardless of its source. 

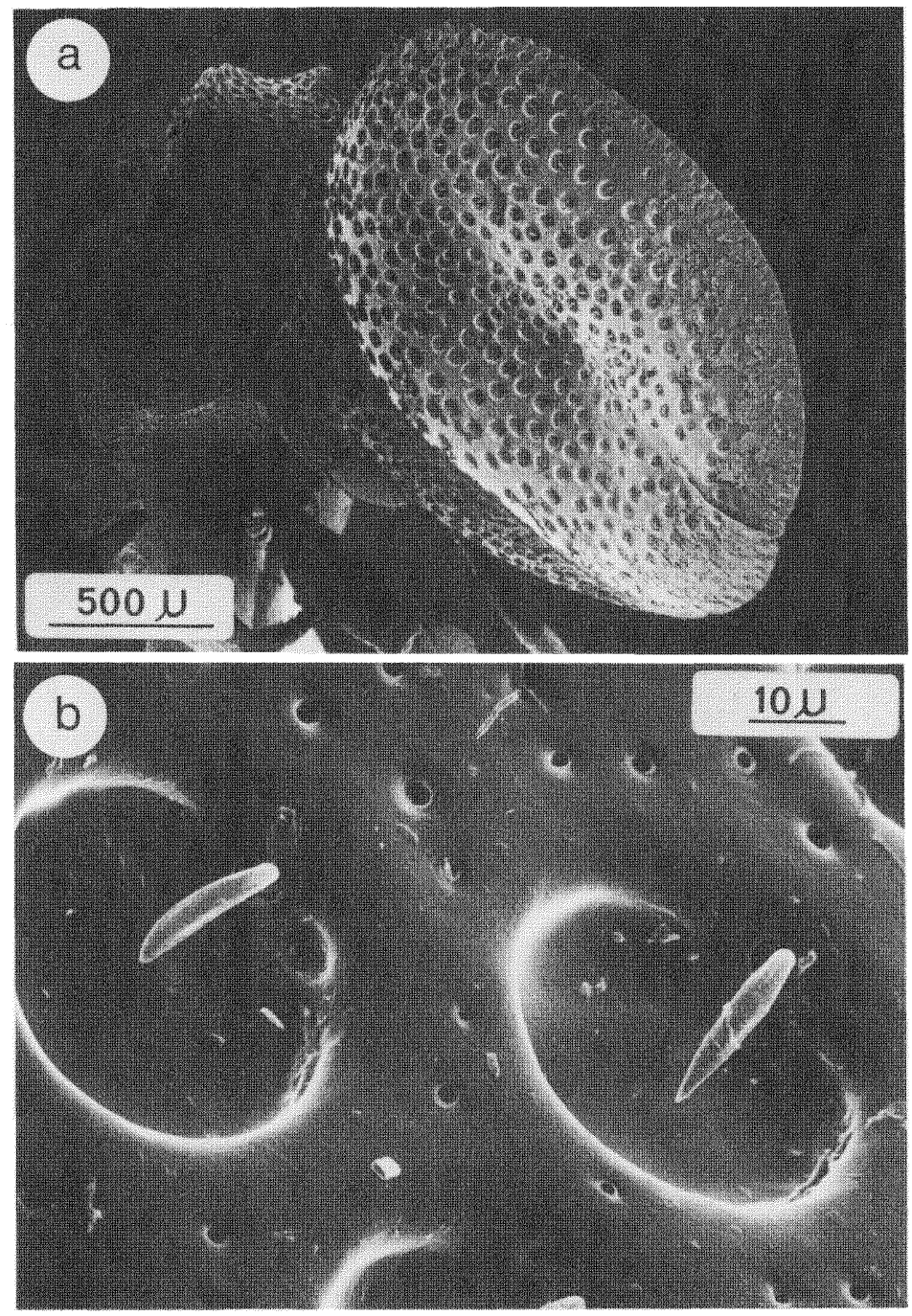

Fig. 1. Zacryptocerus varians (Upper Matecumbe Key, FL). Soldier. a. SEM view of relatively clean cephalic shield. $b$. Surface of clean shield. Note the numerous pores (glandular openings). 

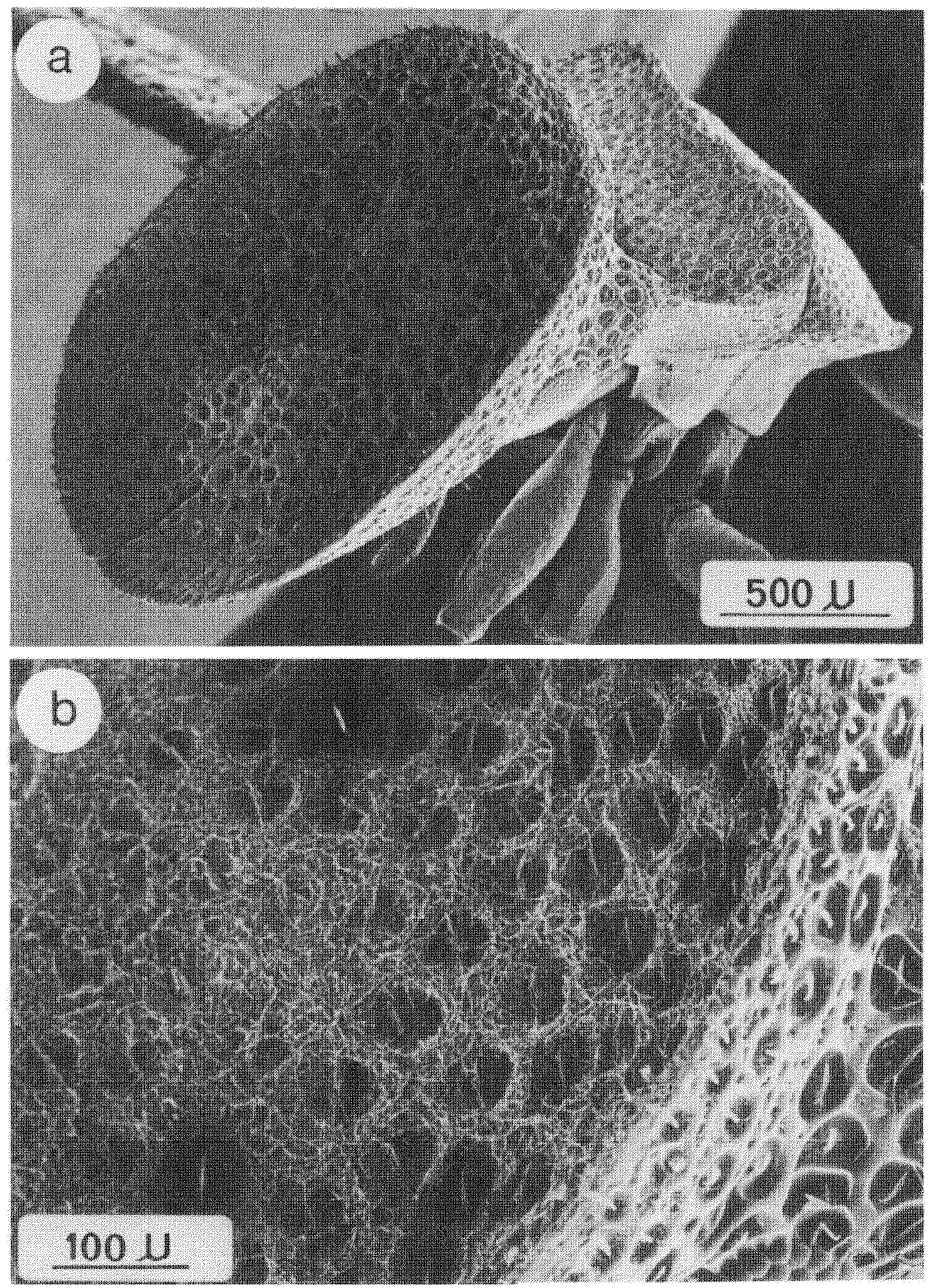

Fig. 2. Z. varians (Lignumvitae Key, FL). a. Soldier head covered with tangled mat of fibers. $b$. Mat of fibers is confined to the cephalic shield. 

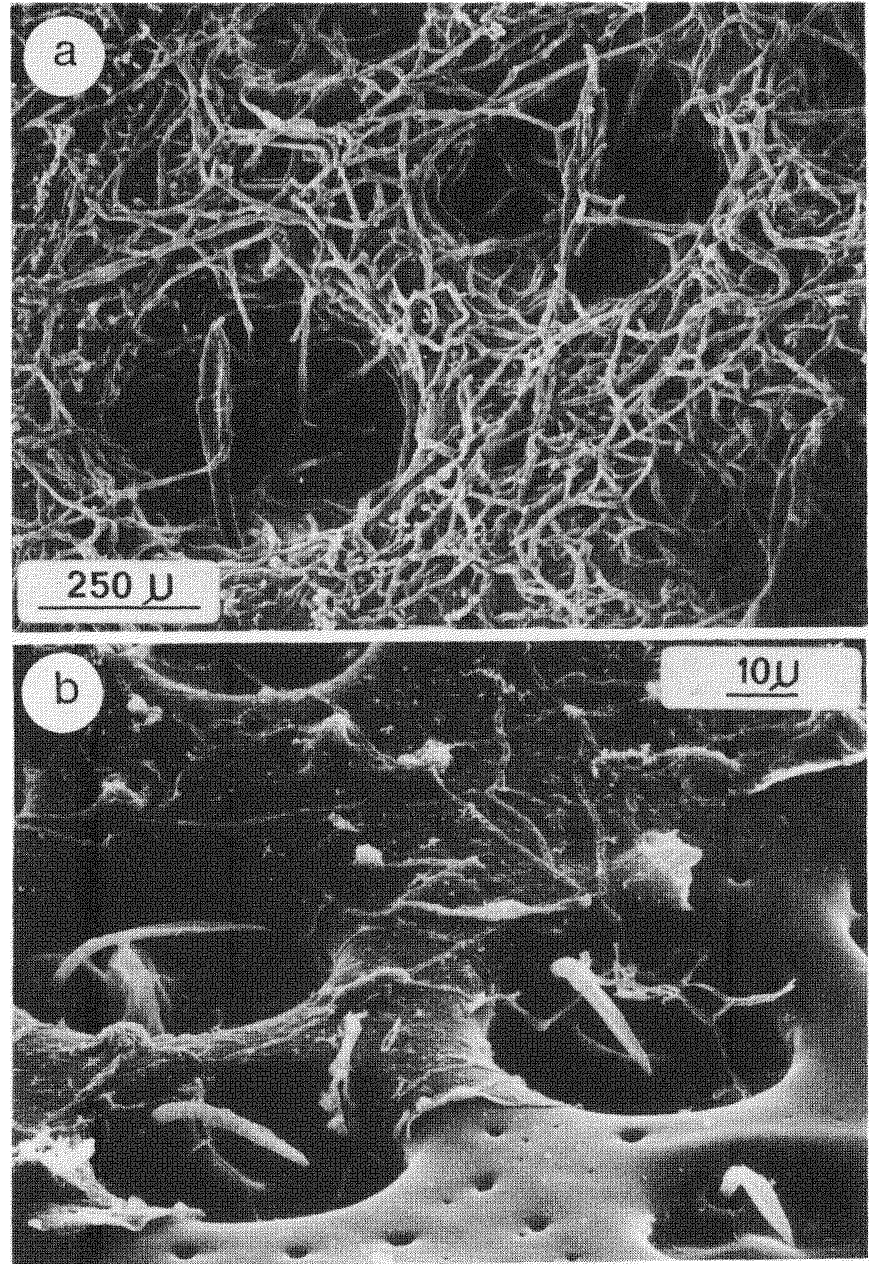

Fig. 3. a. Z. varians (Lignumvitae Key, FL) (same individual as Fig. 2). Close-up of mat covering the large, blade-like setae. b. Z. varians (Card's Point, FL). Soldier. Clean and coated areas of cephalic shield. Note the pores in the clean section and the uniform coating in addition to some fibers in the encrusted area. 

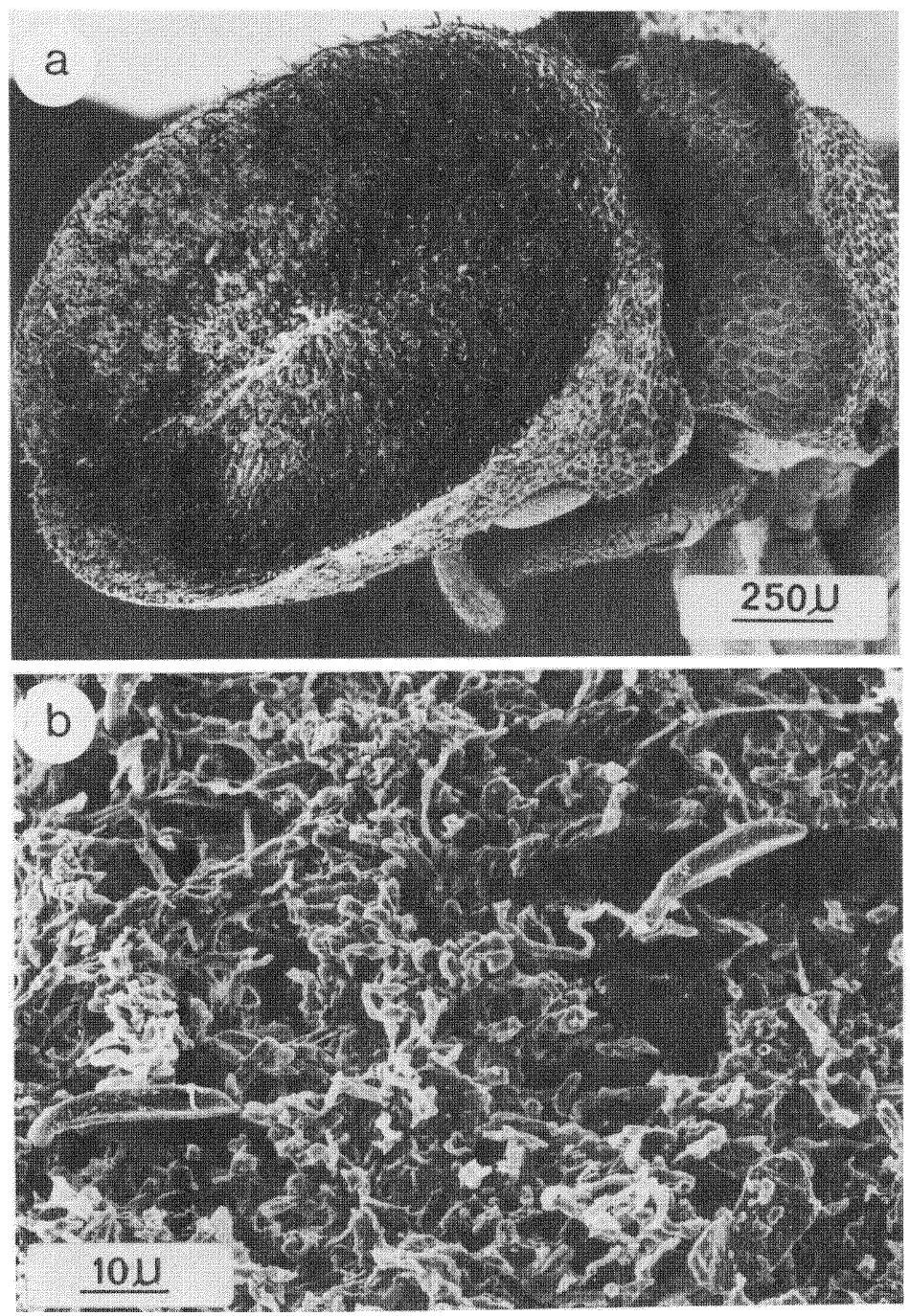

Fig. 4. Zacryptocerus pallens (Kartabo, British Guiana). a. Cephalic shield of soldier. Note central ridge. b. Close up of setae and encrusting materials. 

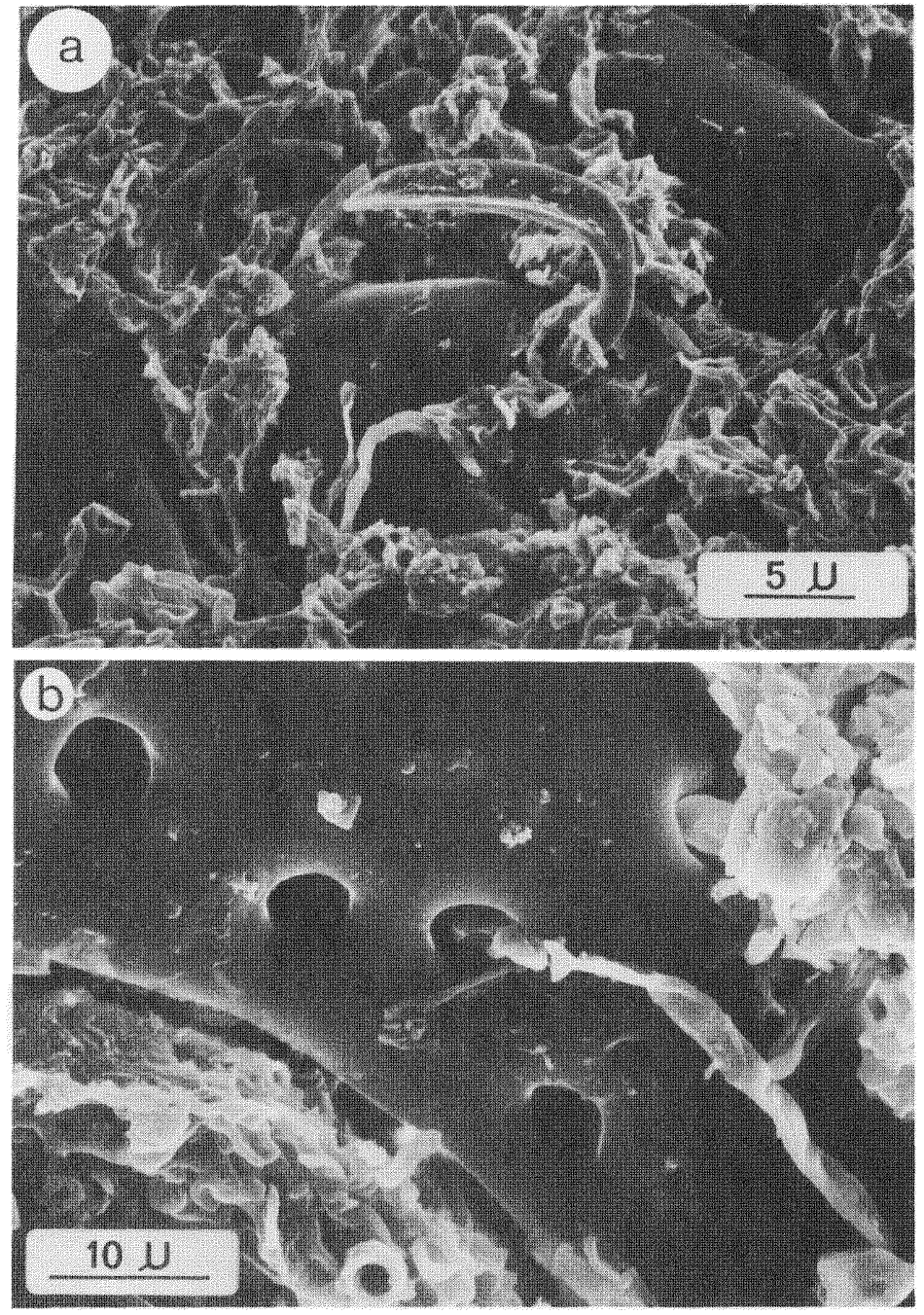

Fig. 5. Z. pallens (same individual as Fig. 4). a. Close up of shoe-horn shaped setae and encrusting ribbons. b. Region on central ridge on which pores are visible. 

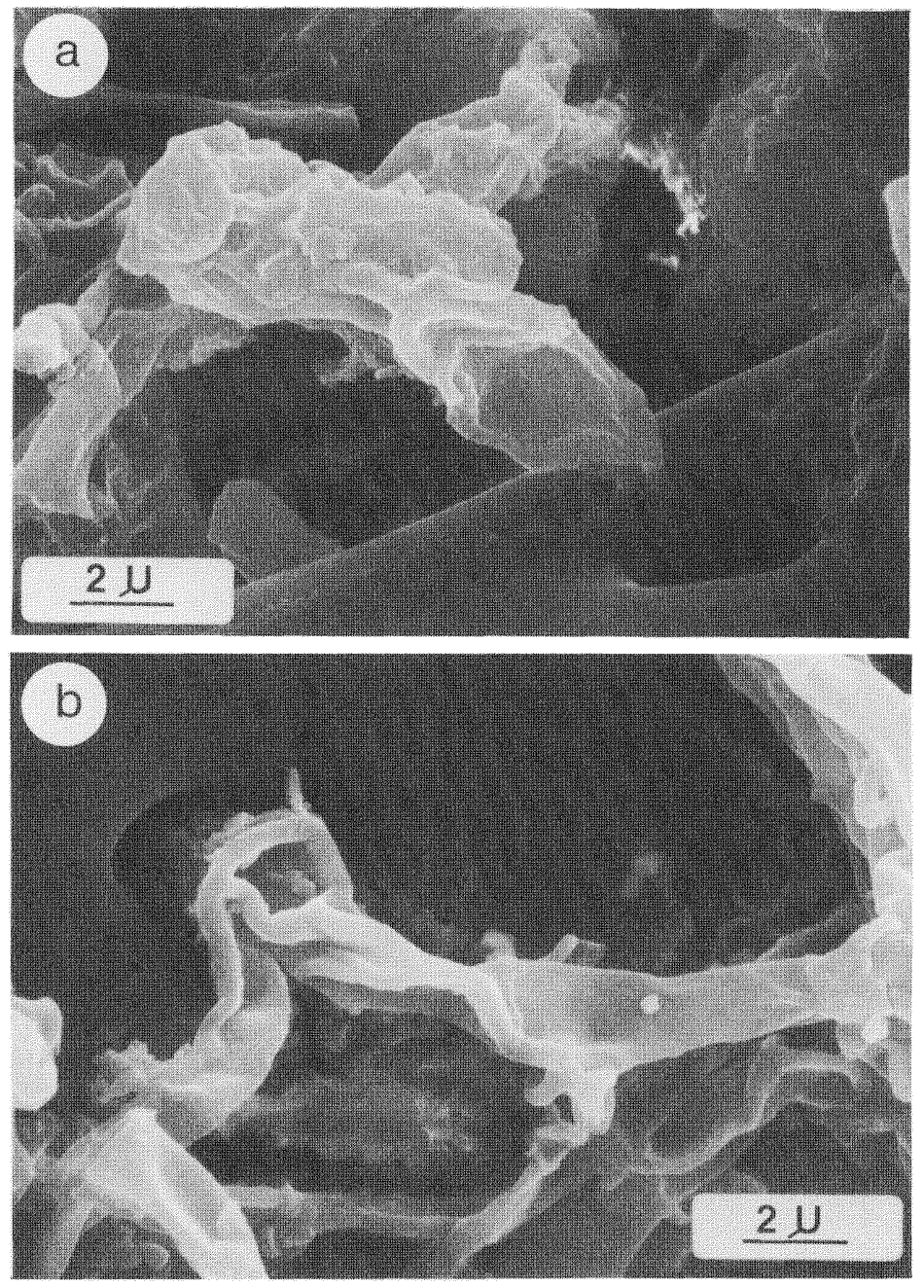

Fig. 6. Z. pallens (same individual as Figs. 4, 5). Pores from which surface coating seems to flow. 

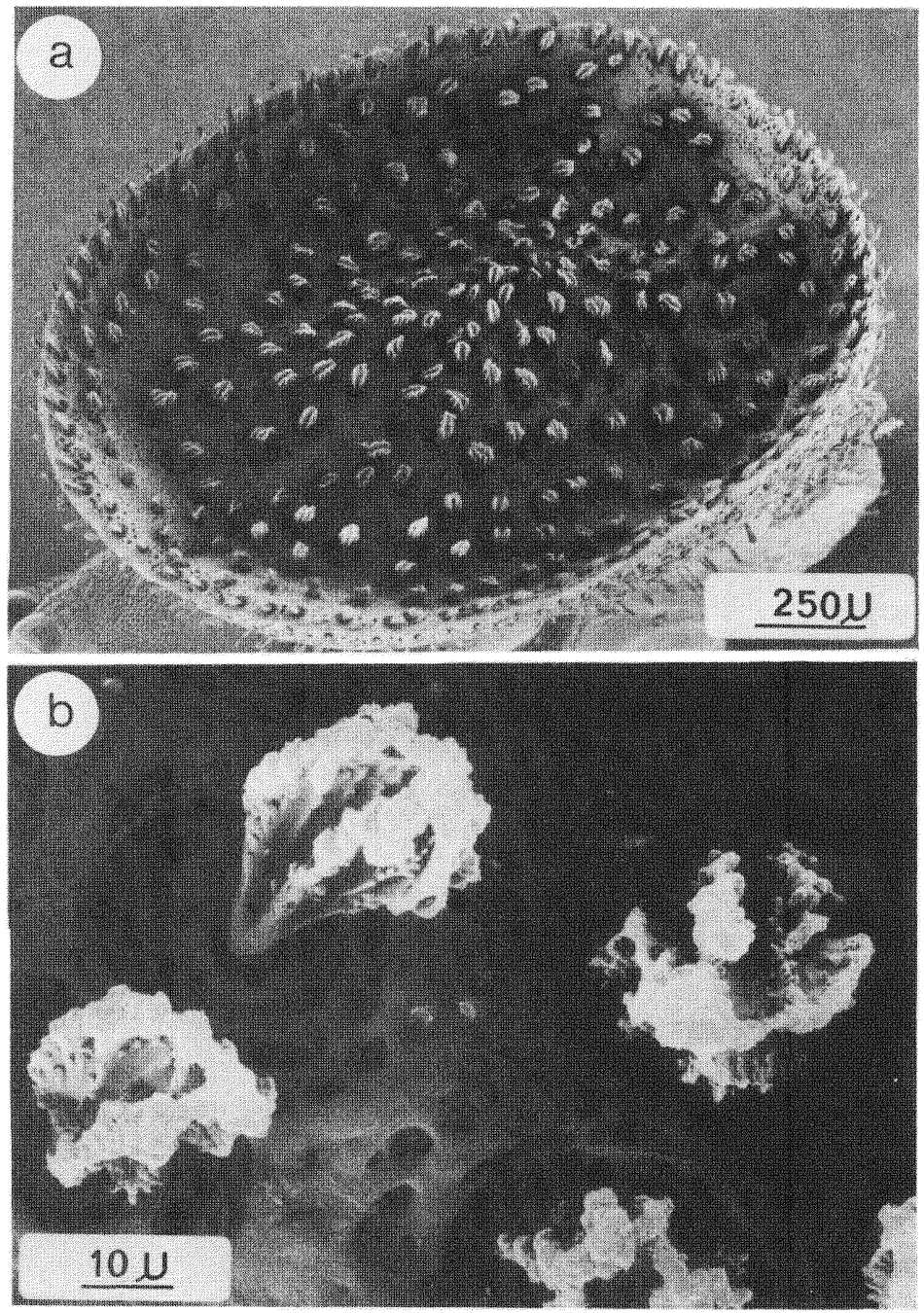

Fig. 7. Z. pallens porrasi (BCI, Panama). Clean soldier. a. Cephalic disc covered with brush setae. b. Close-up of large brush setae. 

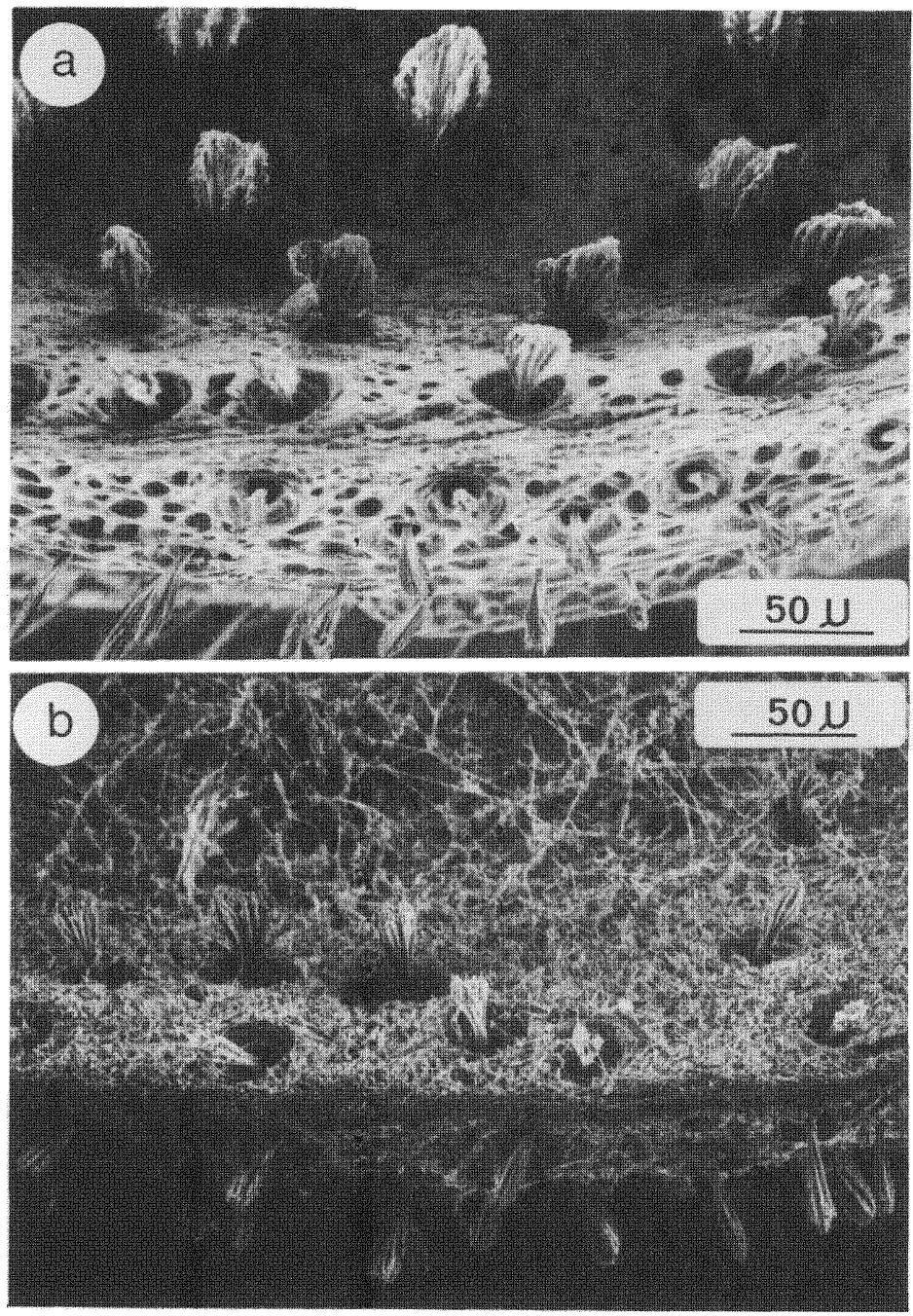

Fig. 8. Z. pallens porrasi. Views from rim of cephalic shield. a. (same individual as Fig. 7). Clean surface. b. Z. pallens porrasi, second soldier, nestmate of individual in Fig. 8a. Shield is so matted that setae beyond the second row are completely obscured. 

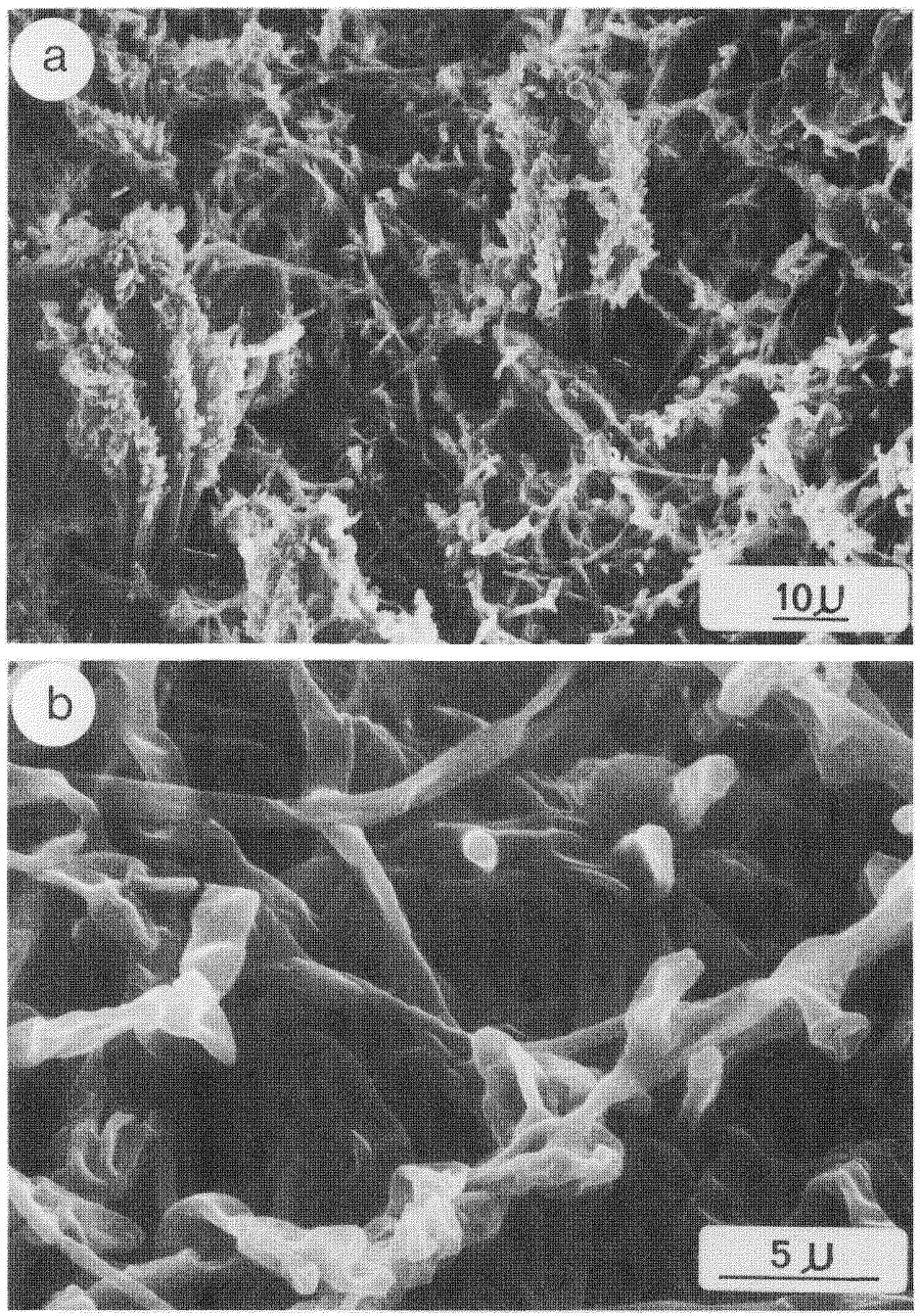

Fig. 9. Z. pallens porrasi (same individual as Fig. 8b). a. Heavily matted cephalic shield, showing tips of brush setae. b. Close-up of fibrous material. 

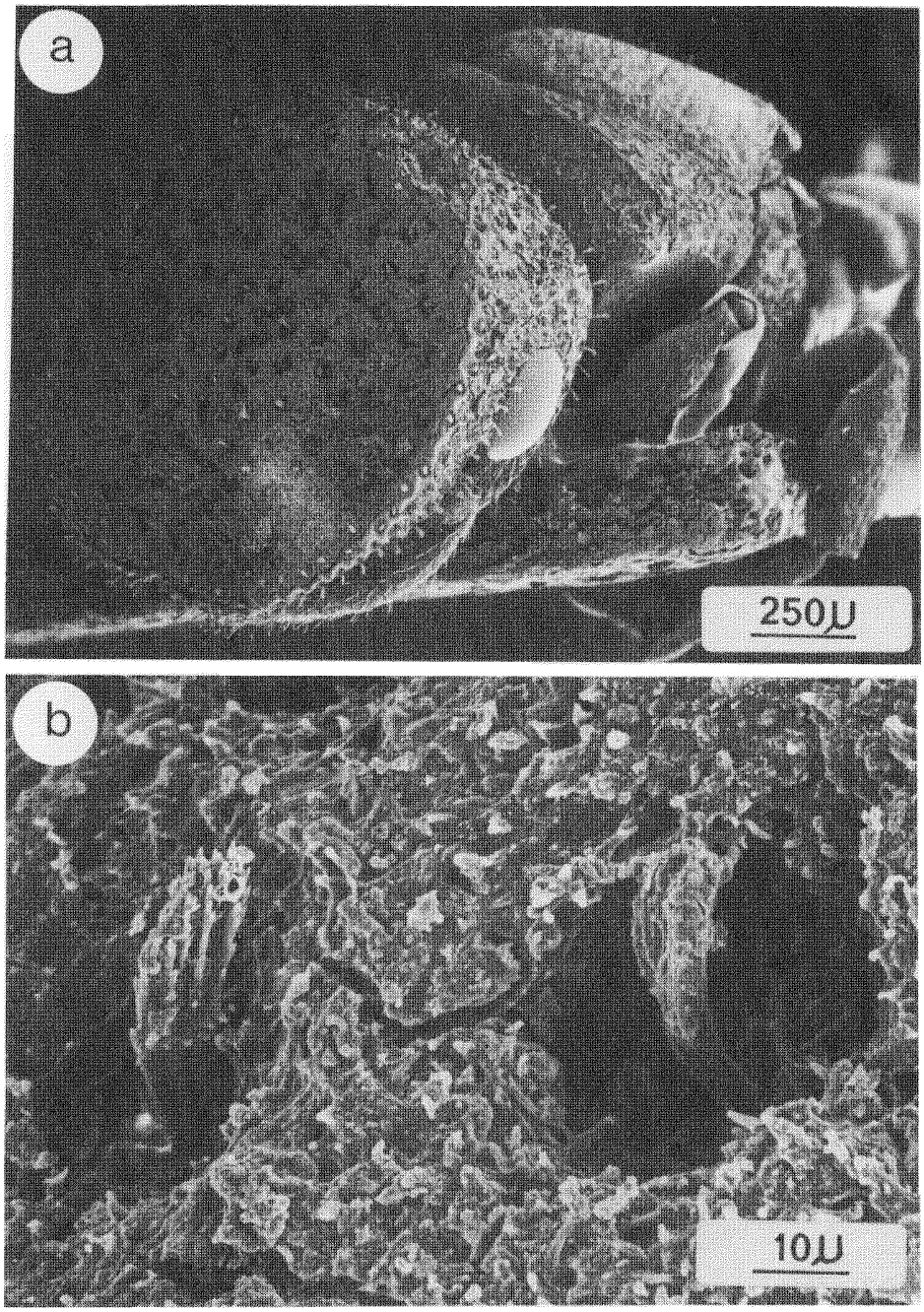

Fig. 10. Z. setulifer (Ancon, Panama). Queen. a. Head is heavily encrusted with material. b. Setae on head, with encrusting material. 

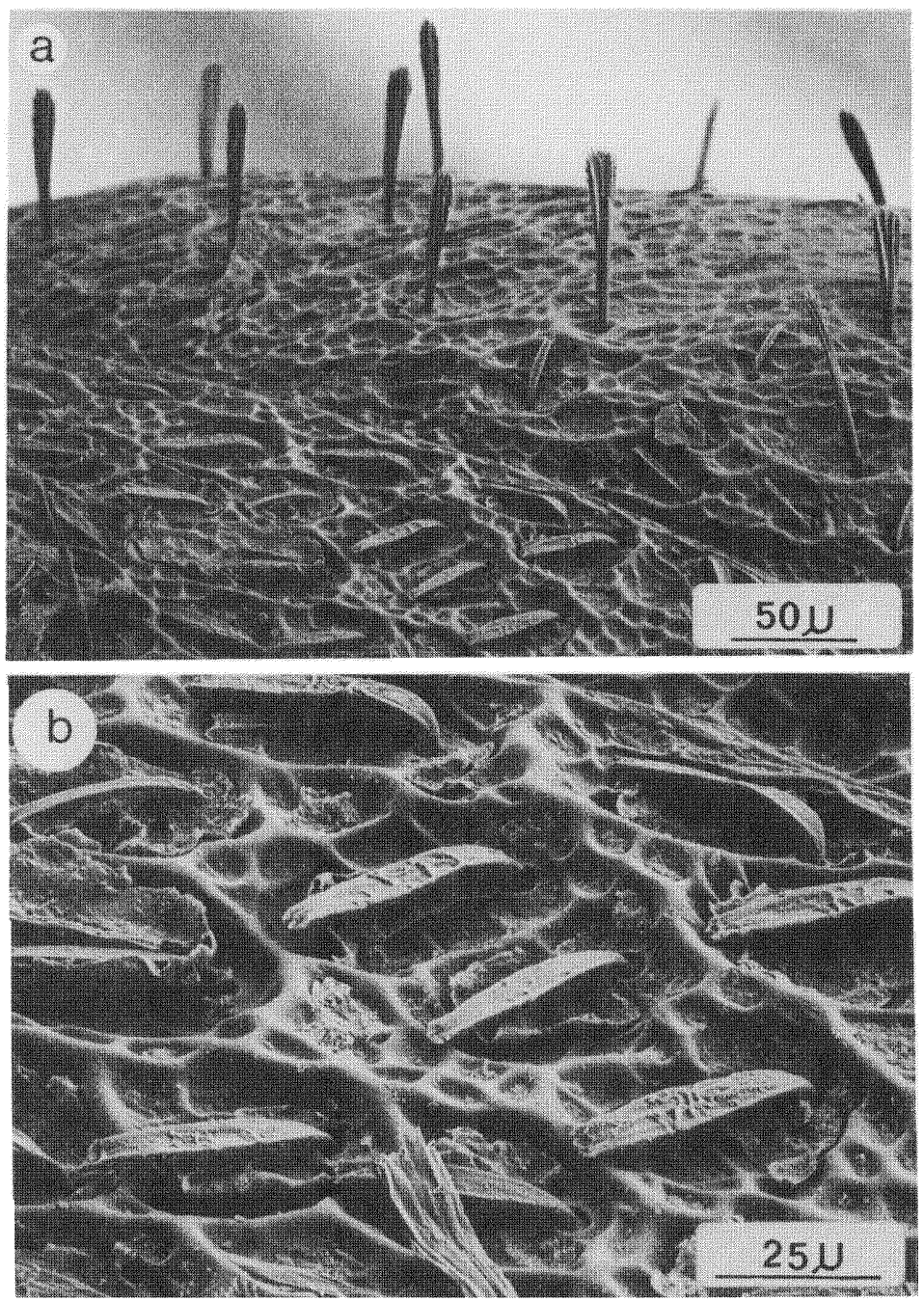

Fig. 11. Z. setulifer (same individual as Fig. 10). Thorax. a. Erect brush setae and second layer of holding setae appressed on surface. $b$. Holding setae. 


\section{ACKNOWLEDGMENTS}

We thank W. M. Maddison for collecting the clean Z. varians specimens, and Ed Seling for valuable SEM work. Funds were provided by NSF Grants PCM 83-01763 and BNS 82-19060.

\section{Literature Cited}

KEMPF, W. W.

1958. New studies of the ant tribe Cephalotini (Hym. Formicidae). Studia Entomol. 1: 1-176.

Holldobler, B. AND E. O. Wilson.

1986. Soil-binding pilosity and camouflage in basicerotine and stegomyrmecine ants (Hymenoptera; Formicidae). Zoomorphology (in press). WHEELER, W. M.

1927. Physiognomy of insects. Q. Rev. Biol. 2: 1-36.

1942. Studies of Neotropical ant-plants and their ants. Bull. Mus. Comp. Zool. 90: $1-262$. 

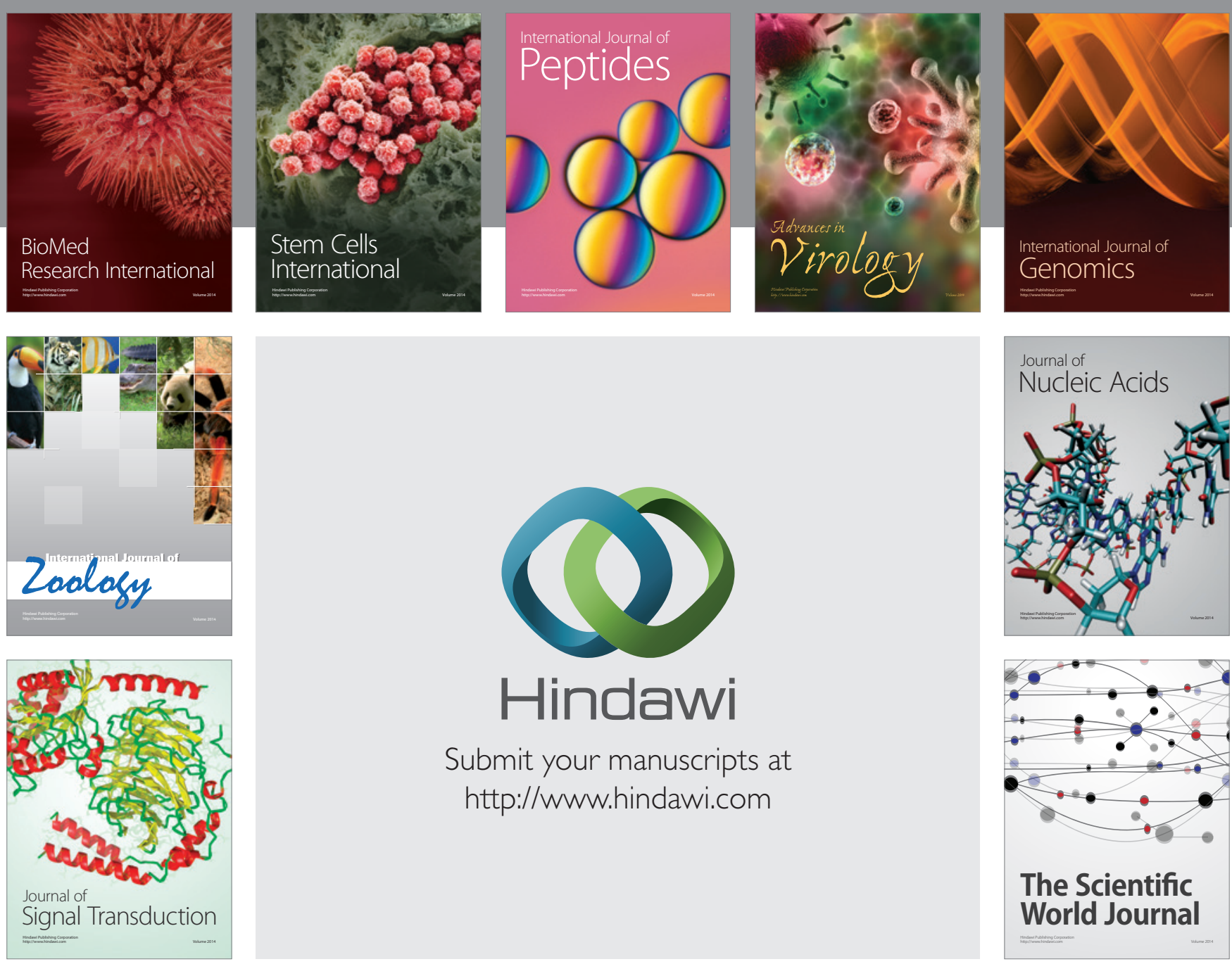

Submit your manuscripts at

http://www.hindawi.com
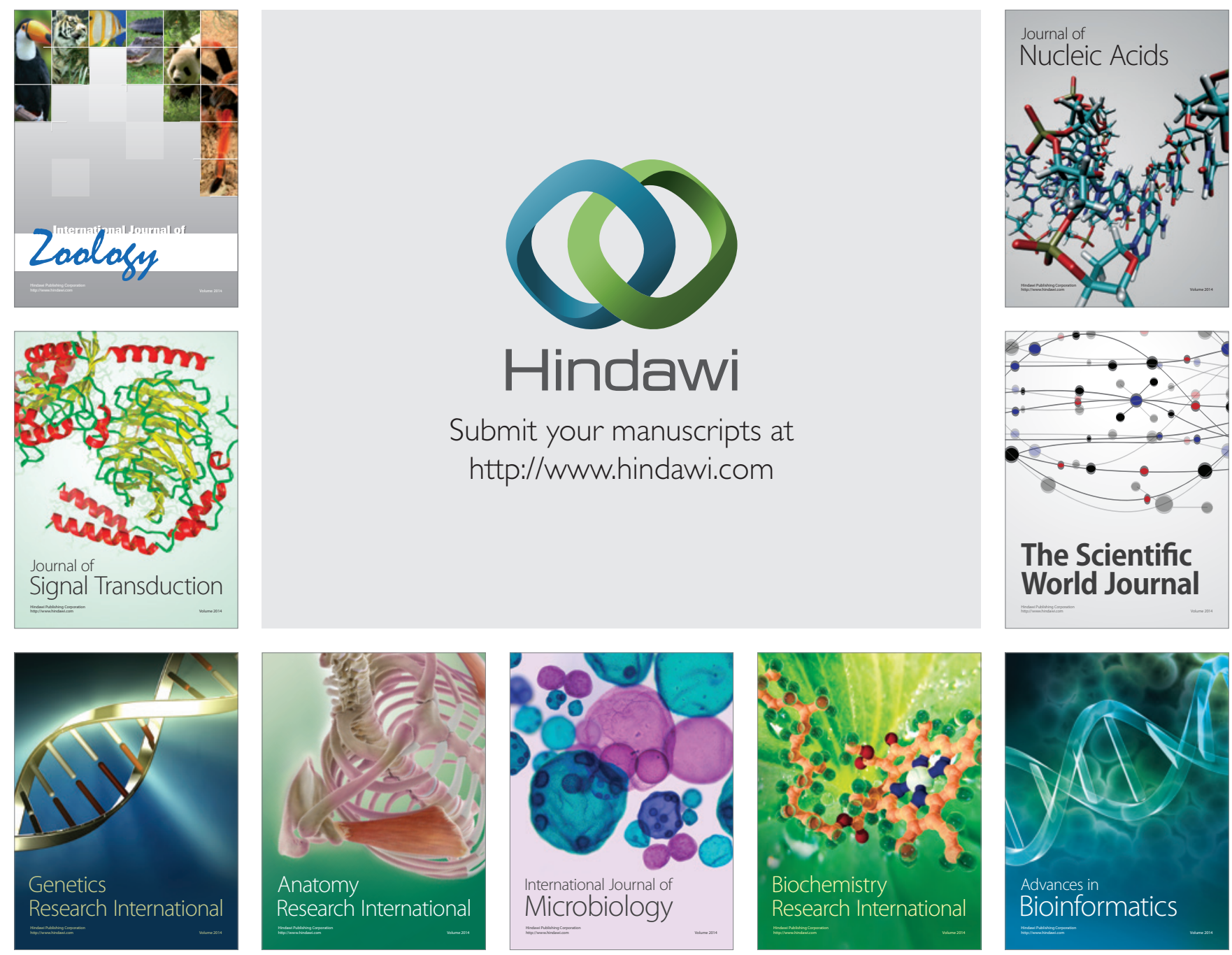

The Scientific World Journal
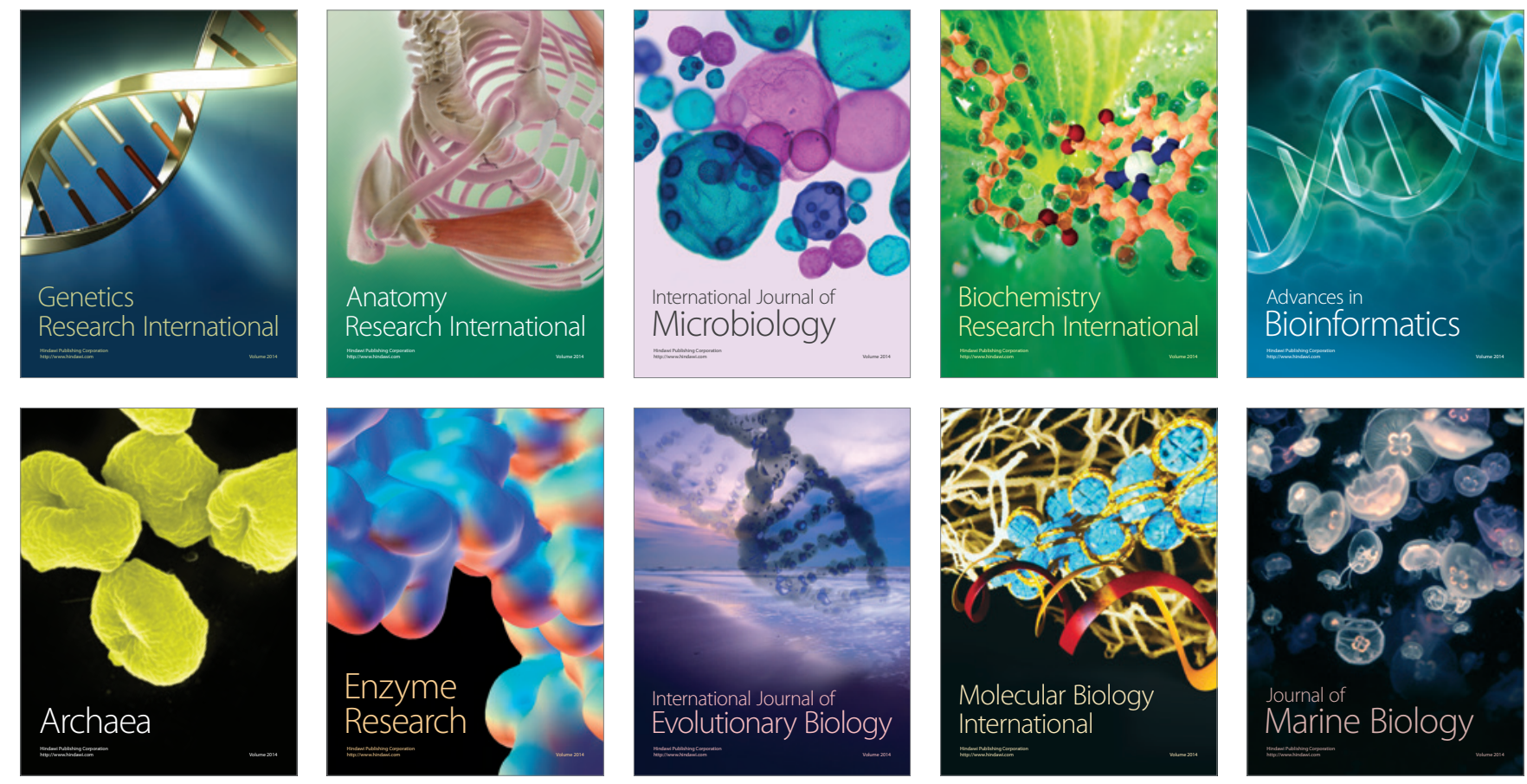